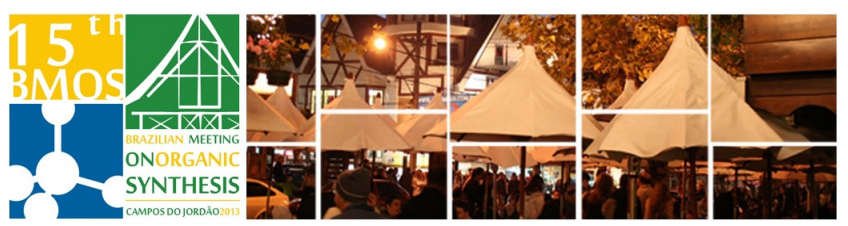

\title{
Seleno-amino acid-based helical polymers for organocatalysis and functionalization of nanoparticles
}

\author{
Gonçalves, A. C. and Dos Santos, A. A.
}

Depto. de Química Fundamental - Instituto de Química - Universidade de São Paulo.*aucegon@gmail.com Keywords: Helical polymer, co-polymer, catalysis.

\section{INTRODUCTION}

The helix shape is found in the most important molecules of the living systems, as the $\alpha$-helix in proteins and the double helix in DNA. ${ }^{1}$ Aiming to mimic the helix conformation founded in natural compounds for new applications is an exiting field of investigation. Since the last decade, phenylacetilenic polymers are extensively investigated and multifunctionalized pendants have been synthesized founding many applications, such as in material science, molecular and ionic sensors, enantiomeric separations and asymmetric catalysis. ${ }^{2}$

\section{RESULTS AND DISCUSSION}

The fundamental core of the polymers investigated in this study was based on 4-ethynylaniline and methyl 4-ethynylbenzoate (Figure 1). These compounds were prepared from 4-iodoaniline and 4iodobenzoic acid, respectively by sequential Sonogashira cross coupling with trimethylsilylacetylene followed by desilylation of the terminal alkyne.
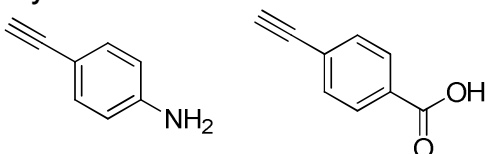

Figure 1. Structure of the precurors of monomers.

The synthesis of the monomers was accomplished by reaction of 4-ethynylaniline with Cbz-protected amino acids leading to the corresponding amides in good yields. 4-ethynylbenzoic acid was used in reaction with alkyl-amino selenides as presented in Scheme1.
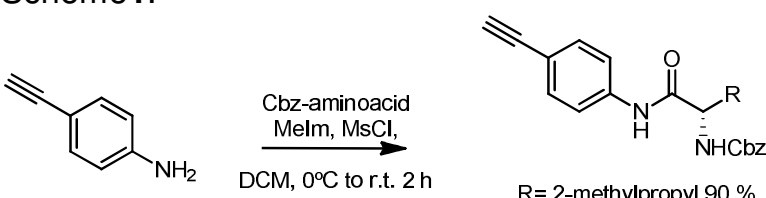

$\mathrm{R}=2$-methylpropyl $90 \%$ $\mathrm{R}=$ Benzyl $92 \%$ $\mathrm{R}=$ Pyrrolidine (Pro) $85 \%$
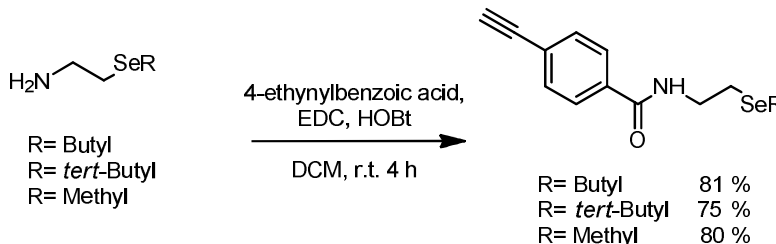

Polymers and copolymers were prepared from monomers presented in Scheme 1 using $[\mathrm{Rh}(\mathrm{nbd}) \mathrm{Cl}]_{2}$ (nbd= 2,5-norbornadiene) as catalyst. The obtained polymers as well as copolymers prepared by co-polymerization of 3-5 with 6-8 in a ratio of 95:5 were analyzed by GPC, showing different ranges of sizes depending on the nature of the selenide precursor. As example, circular dichroism spectra of the copolymers prepared from monomer 5 with 6,7 and 8 suggest a preference of helix sense in co-polymers with bulkiest alkyl selenide groups (Figure 2). The reason for that still under investigation.

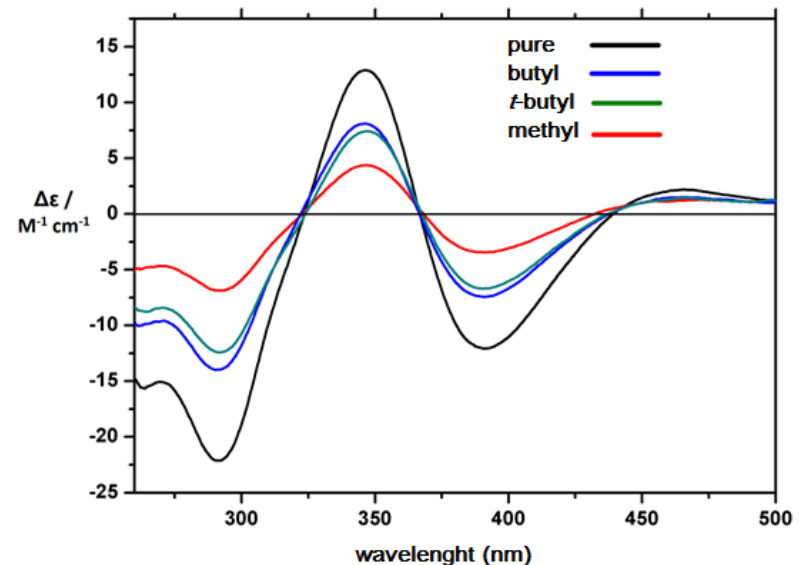

Figure 2. Circular dichroism spectra of some selenobased co-polymers.

The polymer containing a proline residue as well as others will be employed as catalysts and also for organofunctionalization of $\mathrm{Au}$ and $\mathrm{Ag}$ nanoparticles by Se-M interaction.

\section{CONCLUSION}

New class of helical polymers was prepared. The characterization and application of these new materials are under investigation in our group.

\section{ACKNOWLEDGEMENTS}

FAPESP, CAPES, CNPq, SBQ, IQ-USP, NAPCatSinQ.

\section{REFERENCES}

1 Ogunro, O. O.; Karunwi, K.; Khan, I. M.; Wang, X. Q. J. Phys. Chem. Lett. 2010, 1, 704.

2 Yashima, E.; Maeda, K.; lida, H.; Furusho, Y.; Nagai, K. Chem. Rev. 2009, 109, 6102

Scheme 1. Synthesis of the key-monomers 